\title{
Wolfhart Pannenberg bied 'n weerwoord teen die ontwaarding van die geskiedenis
}

\author{
H J Botes (Naboomspruit) \\ Navorsingsgenoot: Hervormde Teologiese Kollege \\ Universiteit van Pretoria
}

\begin{abstract}
Wolfhart Pannenberg's thoughts as answer against the devaluation of history

In this day and age, nobody any longer believes in the redemptive essence of history (Lyotard). One result of modernism is that humankind is left without history, due to a number of factors. Thus, history as such, and more specifically, church history as theological discipline, finds itself in a crisis. Yet, despite criticism that can be levelled against Pannenberg's thinking, his theory, nevertheless, serves as an answer against the devaluation of history. Given that the Person of the Risen Lord as head of the church has, unquestionably, throughout the ages occupied a central position in both the history of the church and that of the world, Pannenberg's consideration of Christ's resurrection, in particular, may stand the church in good stead.
\end{abstract}

\section{INLEIDING}

By die emeritaatsaanvaarding van prof S J Botha, herinner skrywer hom aan 'n geleentheid, waartydens prof Botha sy verontwaardiging te kenne gegee het toe die nut van die vak Kerkgeskiedenis vir die huidige bevraagteken is. Die feit dat Kerkgeskiedenis, en daarmee geskiedenis per se, bevraagteken word, is nie verbasingwekkend nie, trouens dis eie aan die huidige tydsgewrig. Dat teoloz egter geskiedenis, en boonop kerkgeskiedenis vanuit 'n suiwer utilistiese oogpunt beoordeel, en dit dan ook nog as iets wat agterhaal is bevind, vra om nadenke. Barth (1961:29) sê: ons glo - omdat ons aan God, Skepper en Voleinder glo - dat die geskiedenis van alle kreature hul grond en sin vind in die 
geskiedenis van die verbond: om dit nog skerper te stel - in die geskiedenis van Jesus Christus, en dat die wêreldgeskiedenis die heilsgeskiedenis dien. Barth stel (1961:29):

Gott selbst ist das Ziel und das Mass des menschlichen Handelns in der Welt ... Gott selbst ist der Freie, vor dem man sich hinter kein Programm verschanzen darf ... Dass Gott selbst als der Herr erkannt wird, das ist der entscheidende Unterschied zwischen dem Vorsehungsglauben und aller Gesichtsphilosophie.

Dit alles dui op die heerskappy van Christus in die geskiedenis. In hierdie artikel, sal 'n beskeie poging aangewend word om vanuit dié perspektief Kerkgeskiedenis as teologiese dissipline te legitimeer.

\section{NOODSAAK VIR ONDERSOEK}

Soos reeds ter inleiding opgemerk, word geskiedenis nie oraloor hoog aangeslaan nie. Die Franse postmoderne filosoof, Lyotard, skryf van ons tyd (kyk Kuiken 1993:8): dat niemand meer glo in die verlossende essensie van die geskiedenis nie, vanwee die enorme krisis wat meegebring is deur twee wêreldoorloe,, gevolg deur 'n byna veertig jare lange koue-oorlog en dies meer. Volgens Christopher Lasch (1979:25, 26) die Amerikaanse kultuurfilosoof, is die ontwaarding van die verlede een van die belangrikste simptome van die huidige kultuurkrisis. Hy wyt die verloêning van die verlede aan die opbloei van die narsistiese kultuur. Foucault (kyk Bakker 1996:129), afkomstig uit die Franse strukturalisme, wys op die krisis waarmee die moderne historikus opgeskeep sit omdat die metodologie van die historiese wetenskap ontdaan is van vrae ten aansien van rasionaliteit en die teleologie van die ontwikkeling van gebeurtenisse. Bakker (1996:18, 19), skryf in sy indrukwekkende studie wat handel oor die legitimasie van die konsep "geskiedenis", dat die uitholling van die Christelike boodskap die eintlike rede is vir die krisis waarin geskiedenis en kultuur verkeer. Hy stel dit soos volg:

De grote vergeefsheid die over ons kwam vanwege het Niets, de "unheimliche Gast" (Nietzche), moet, naar onze mening, mede worden verklaard uit die massale ontgoocheling ondervonden aan de verkondiging van de kerk. Een ontgoocheling die, naar het ons voorkomt, voor een belangrykk deel geweten 
moet worden aan een diepgewortelde twyfel, door en eeuwenlange kerklyke traditie gevoed, ten aanzien van de juist ook intellectuele! geloofwaardigheid van het bybels getuigenis.

Om stand te kunnen houden tegen de aanvallen van buiten, moest het getuienis van profeten en apostelen, zo meende men al zeer vroeg, worden aangepast! Het moest zich handhaven in een milieu dat het geestelyk stempel droeg van het Hellenisme. Het moest in denkvormen gegoten worden, die algemeen werden aanvaard en daarom onbetwyfelbaar werden geacht. De denkvorme die zich, naast het begrip natura (natuur) hiervoor uitstekend scheen te lenen, was het begrip historia (geskiedenis), dat bovendien nog, zo meende men (ten onrechte!), afkomstig was uit de Schrift zelf.

Dit alles, saam met die linier-historiese denkwyse, wat algaande deur die Christendom as toenmalige invloedryke geestelike mag in Europa gevestig is, het gelei tot 'n akute historisering van die Bybel se kerugma. Die groot vooruitgangsisteme vanaf Voltaire, tot en met Proudhon, en vanaf Herder tot en met Hegel en Marx, was uiteindelik die gesekulariseerde vorme van die bogenoemde proses waardeur godsdiens gesien is as 'n tydelike verskynsel. Dit het daartoe gelei dat die Christendom nie meer as 'n historiese en geestelike mag van gesag is om mee rekening te hou nie. Sedertdien het geen denkende mens daaroor gepeins of die voorsienige hand van God sigbaar mag wees in die geskiedenis van die Christendom nie. Lasch (kyk Bakker 1996:20), vra na aanleiding van die onmiddellik voorafgaande opmerking: As 'n mens nie meer glo in die voorsienigheid van God in die geskiedenis nie, waar dan wél in?

In de vooruitgang? In de opvoeding van de mensheid tot humaniteit (Herder)? In de klassenlose maatschappij (Marx)? In het democratiese liberalisme (Fukuyama)? Ook dat lyk na twee wêreldoorlogen, de uitvinding van de atoombom, de inburgering van genocide en de etnische zuivering in centraalEuropa een nogal boude bewering. De feitelyke situasie noopt veeleer tot het inzicht, dat de historische loop der dingen in zichzelf geen aanwysbare steunpunten bevat, die het spreken van 'goddelÿke providentie', van een 'profetische zaak' of van een 'verlossende essentie' rechtvaardigen kunne. "Chr Lasch typeerde de daarmee ontstane cultuurcrisis als volgt: de moderne 
mens is de mens zonder cultuur, zonder geschiedenis, zonder sociaal verband, zonder moraal, voor wie niets anders rest dan navelstaren en het stervenaar instant bevrediging.

Dit kom alles daarop neer, dat die mens van ons dag, ' $n$ mens sonder geskiedenis is. Dit moet op die rekening geplaas word van die bestaan van die Christendom oor 'n periode van tweeduisend jaar. Bakker (1996:21), vat die verloop van die ontwikkeling wat gelei het tot die huidige toestand van die ongeloofwaardigheid van die geskiedenis in 'n neutedop saam:

... eerst - en al heel gauw -, werd die God van de bybel ongeloofwaardig. Dat gebeur al in het paradysverhaal in de bybel zelf? Toen moest den bybel geschiedenis worden van de uitverkoren mens, kerkgeschiedenis dus. Vervolgens word de kerk ongeloofwaardig. Toen moest de bybel geschiedenis worden van de religieuze mens, godsdiensgeschiedenis dus. Vervolgens werd de religieuze mens ongeloofwaardig. Toen werd de geschiedenis vooruitgangschiedenis en kon de bybel gesloten blyven. Tenslotte werd die geschiedenis zelf ongeloofwaardig en daarmee de mens zelf".

De schets laat zien: de bybel zál en moet geschiedenis zýn. Dat staat vast. Anders gezegd: de geloofwaardigheid van de Schrift verhoudt zich rechteveredig tot de geloofwaardigheid van de geschiedenis. Valt de laaste weg, dan valt ook de eerste weg. En omgekeerd, valt de cerste weg, dan ook de laaste. Zie daar het nihilistisch dilema, waarvoor onze generatie is gesteld, vrucht van negentienhonderd jaar historiserend Christendom.

Die huidige toestand van geskiedenisloosheid, wat die oorsaak is van die kultuurkrisis en die ongeloofwaardigheid van die kerk, is te wyte aan die kerk self. Bakker (1996), toon aan dat die permanente vervreemding van kerk en Christendom van die Skrif - die oorsprong en die bron van die kerk se bestaan, die oorsaak van die ongeloofwaardigheid van die geskiedenis is. Die verloěning van die Skrif se gesag, moet noodwendig uiters destruktiewe gevolge vir kerk en wêreld hê. Die vraag word dus gevra: of die geloofwaardigheid van die geskiedenis nie gesoek moet word in die betroubaarheid van die Woord self nie? Indien wel, moet die mens noodwendig volgens die beginsel terug- 
gewerp word op ' $n$ on-historiese instansie, naamlik op 'n betroubaarheidspremisse wat nie uit die mens spruit nie, en ook nie uit die geskiedenis voortkom nie, maar wat setel in die wese van die Woord self - naamlik daarin, dat wat die God van die Woord sê, doen Hy ook. Om dié "onhistoriese betroubaarheid" as vertrekpunt te neem vir geskiedenisnavorsing, open verrassende perspektiewe. Die tema waaraan die Bybel immers besondere aandag gee, is dat God die mens regverdig terwille van Homself, ondanks en in weerwil van die menslike geskiedenis. By alles leer die Bybel dat Hy dit doen deur sy Woord wat tewens ook sy Daad is. Die geloofwaardigheid van die geskiedenis, en ook die kerkgeskiedenis, moet in gesoek word in die geloofwaardigheid en betroubaarheid van die Skrif - wat God se geopenbaarde werklikheid is.

\section{PANNENBERG SE BETEKENIS VIR KERKGESIEDSKRY- WING}

In die lig van die gestelde probleem ten opsigte van die geskiedenis, word vervolgens gekonsentreer op W Pannenberg (gebore 1928), se geskiedenisbeskouing. Pannenberg se roep se teoriee roep baie vrae na vore wat nie noodwendig sonder kritiek aanvaar kan word nie. Nogtans is sy teologiese denkarbeid wat hy uiteensit binne kader van die geskiedenis uiters stimulerend. Veral Pannenberg se betoog oor Christus, die Vleesgeworde Woord se historiese opstanding, bied antwoorde op die probleem van die vervreemding wat tussen kerk en Woord ingetree het, waardeur 'n devaluasie van die geskiedenis ontstaan het.

Danksy die invloed van die kerkhervorming, het kerkgeskiedenis wat sedert 1585 as afsonderlike teologiese vak beoefen is, die teologiese dissipline geword wat op toegespitste wyse gesoek het na die oorsprong en wese van die kerk. Nie net in die Bybel nie, maar ook in die geskiedenis van die Christendom is gesoek na die hartslag van die Christelike kerk. Veral is die kerkgeskiedenis die dwang opgelê om die konfessionele standpunte van die kerk te legitimeer. Deur die eeue heen was die uitgangspunt van kerkgeskiedskrywing, met die kerk as objek vir interesse, Jesus Christus se Heerskap, wat die primaat van die Christelike kerk is.

Die ontkenning van Christus se historiese opstanding, vervreem nie net die kerk en Woord nie, maar plaas die bestaan van die kerk op die spel, waardeur teologie- 
beoefening, en vanselfsprekend dan ook kerkgeskiedenis as teologiese dissipline 'n kerkhofbedryf word. Kerkgeskiedenis, soos uiteraard ook die ander teologiese vakke binne kader van 'n teologiekonsepsie dat Jesus nié Christus is nie, word dan 'n studie, of 'n onderdeel van die sosiale wetenskappe.

Pannẹnberg as dogmatikus gee blyke van 'n verstaan dat die Christelike kerk vanuit die oorgelewerde geskiedenis van Christus se opstanding lewe. Perspektiewe wat hy in die verband ontvou, bied besondere moontlikhede aan die kerkhistorikus se kritieswetenskaplike vertrekpunt.

In teesstelling tot die meeste twintigste-eeuse teoloe, wat gewoonlik in die Kantiaanse tradisie staan, is die denke van Wolfhart Pannenberg gevorm deur die filosofie van Hegel (Van de Beek 1994:116). Sy geskrifte gee deurgaans blyke van deeglike filosofiese geskooldheid en virtuose begaafdheid wat hom in staat stel om op 'n besondere wyse die geskiedeniswetenskap, die eksegese en sistematiese teologie met mekaar te verbind.

Alhoewel Pannenberg deur Barth beïnvloed is, by wie hy tydlank gestudeer het, het hy van meet af, syns insiens, Barth se relativering van die betekenis van die historiese kritiek afgewys (Bakker 1996: 221). In navolging van Gerhard von Rad, het Pannenberg verkies om te praat van oorleweringskritiek. Die teologie in Duitsland, tussen die twee wêreldoorloe, is grootliks bepaal deur die dialektiese teologie wat deur twee denkrigtings gedomineer is, naamlik die Barthiaanse rigting - die sogenaamde teologie van die Woord, en die Bultmanniaanse rigting - die sogenaamde kerugmatiese teologie.

Uit die rigtings het weer nuwe rigtings en skole ontstaan. Taal en geskiedenis het hoofsaaklik die werklikheidsgebiede geword waarop die besinning van teoloz gevestig geraak het. Die intensies van die dialektiese teologie is algaande op verskillende maniere verwerk en uitgelê. Samevattend kan beweer word dat die Bultmannskool, teologies primêr geinteresseerd was in die woord as taalgebeure. Dus die fokus was gerig op: de verba. Ernst Fuchs (gebore 1903) en Gerhard Ebeling (gebore 1912), was van dié benadering eminente eksponente (De Knijff 1980:129).

Pannenberg en sy skool, het hulle teen dié agtergrond verdiep in die feitelikheid van die geskiedenis - de facta. Weliswaar beteken dit nie dat de verba, losstaan van de facta nie - maar dat die feite die oorhand het, en dat woorde die feite interpreteer. 
Laasgenoemde opmerking bring 'n mens nou digby Pannenberg se geskiedenisopvatting. Geskiedenis, sê Pannenberg (1959:22), is die alomvattende horison van die Christelike teologie. Alle teologiese vrae en antwoorde vind hulle betekenis binne kader van die geskiedenis wat God met die mensheid en deur dié met sy skepping maak. Dit is geskiedenis wat voortstu na 'n toekoms wat tans nog verborge is vir die wêreld, maar tog reeds nou al openbaar is in Jesus Christus.

Dié opvatting van Pannanberg, het meegebring dat hy die opvatting van Bultmann, wat gestel het dat die geskiedenis opgelos word in Geschichtlichteit, sterk sou afwys. Terselfder tyd het Pannenberg, Barth se, syns insiens, se bowe-historiese geloofsgrond bestry.

\section{PANNENBERG SE GESKIEDENISBESKOUING}

In sy Bybels-teologiese werk: Grundzüge der Christologie (1964), gee hy 'n uiteensetting van sy teologie binne die raamwerk van die geskiedenis. In die geskiedenis, stel hy, vind die openbaring plaas. In die geskiedenis ontmoet ons God.

Pannenberg handhaaf die siening dat die tweedeling, wat kenmerkend geword het van Europese denke in die twintigste eeu, naamlik dat skerp onderskei moet word tussen die wêreld van die empirie en die wêreld van die geloof, 'n onhoudbare teenstelling is. Vir hom staan geloof nie los van die ervaring, die etiek nie van die kennende, en God nie van die geskiedenis nie (kyk Robinson 1967:5-22). Dit sou ook dan die rede wees hoekom hy 'n afsonderlike heilsgeskiedenis onbestaanbaar naas algemene geskiedenis vind. Heilsgeskiedenis is nie 'n seleksie uit, of bepaalde interpretasie van die gewone geskiedenis nie. Inteendeel, die gewone geskiedenis wat die historikus ondersoek, is die openbaring van God (1959). As Pannenberg van historiese werklikheid praat, verwys hy altyd na Israel.

Dié volk het deurentyd die werklikheid van hulle God nie in 'n ewige herhalende mitiese oergebeure beleef nie, maar in die opeenvolging van telkens nuwe gebeurtenisse. Hierdie argument setel hy dus in die geloofstradisie self - want vir Israel hoort geskiedenis en openbaring altyd wesenlik bymekaar. Dié Godservaring bied vir Pannenberg die grondslag vir die verstaan van die werklikheid as 'n reguitlynige voortbeweeg van gebeure na 'n bestemde doel. Israel het die geskiedenis verstaan as 
gebeure wat uitgestrek tussen belofte en vervulling ingesluit is. Dié spanning gee aan geskiedenis 'n onomkeerbare doelgerigte karakter met 'n sekere toekomstige vervulling. Pannenberg se onderhawige beskouing is sterk beinvloed deur Oscar Cullmann, met sy boek Christus und die Zeit (1946). In dié werk huldig Cullmann die opvatting van heilsgeskiedenis as reěle geskiedenis, bestaande uit besondere heilshistoriese momente wat as 'n uitgestrekte reguitlyn (soos 'n rooi draad) deur die tyd strek, met die skepping as vertrekpunt, en die voltooiing as eindpunt waarvan Christus die middelpunt is. Pannenberg, lê die klem egter ietwat anders as Cullmann, in die sin dat eersgenoemde stel dat die spanning tussen belofte en vervulling die hele geskiedenis konstitueer. Wat Pannenberg stel, is ten diepste dat geskiedenis, as die totale wêreldgeskiedenis, die werklikheid in geheel is (1959:27).

\section{VERHOUDING GOD EN GESKIEDENIS, ALDUS PANNEN- BERG}

Pannenberg poneer dat wat in die openbaring geopenbaar word, nie God self in sy volheid is nie, maar veeleer 'n stukkie geskiedenis tussen God en mens. Openbaring kom altyd tot die mens deur bemiddeling van die geskiedenis. In die $\sin$ is openbaring altyd indirek.

Openbaring in onmiddellike sin, sal plaasvind aan die einde van die tyd, in die paroesie: De Knijff (1980: 138) vat die tese van Pannenberg duidelik saam:

De parousie omvat het geheel van de geschiedenis. Pas in de parousie openbaar God zich als de universele God van wêreld en mensheid, als Schepper en Voleinder van heel het historisch proses. De ganse geschiedenis zal dan openbaring van God zijn; Gods openbaring en geschiedenis openbaring vallen dan samen.

Bakker (1996:225) se kommentaar op De Knijff se vertolking van Pannenberg se tese van die verhouding God en geskiedenis, soos verwoord in die onmiddellik voorafgaande aanhaling is: 
Duidelyker kan het niet worden gesegd: de openbaring is identiek, valt samen met het proces van de algemene wêreld-geschiedenis, nu nog indirect en voor een groot deel verborgen, straks, in het einde, manifest en onmiddellyk evident. God openbaart zich in en door de geschiedenis! Al is het dan voorlopig mondjesmaat.

Die gevolgtrekking van De Knijff is, dat vir Pannenberg die bestudering van gewone godsdiens en volksgeskiedenis in wese nie verskil van openbaringsgeskiedenis nie. (Dit uiteraard werp allerhande vrae op, soos onder andere byvoorbeeld: was die feite wat die profete en apostels meegedeel het werklik gewone feite sonder dat dit as buitegewoon gekategoriseer kan word?)

\section{DIE HISTORIESE OPSTANDING VAN CHRISTUS}

Die hele kwessie van Christus se liggaamlike opstanding as historiese werklikheid neem in Pannenberg se geskiedsvisie 'n sentrale plek in.

Pannenberg, beskou die opstanding van Christus as die antisipasie van die geskiedenis. Daarom is die opstanding, die sleutel tot die verstaan van die Universalgeschichte, wat slegs vanuit die einde te begryp is. Indien die einde prolepties aanwesig is in die opstanding van Jesus, dan is daarmee die historiese bewys gelewer vir die waarheid en die werklikheid van die Godsgeskiedenis. Van die historisiteit van die opstanding van Jesus hang die hele konsepsie van die Universalgeschichte af. Val die historiese opstanding weg, dan stort die hele gebou in duie. Sonder die historiese opstanding verloor die Universalgeschichte bestaansreg in die werklikheid. Dit is boeiend om kennis te neem van hoe Pannenberg te werk gaan om dié historiese bewys van Christus se opstanding te verduidelik. Met omsigtige formulering stel Pannenberg, dat die opwekking van Jesus as historiese gegewe aangedui kan word, as die ontstaan van die oer-Christendom, wat immers teruggryp na die verskyning van die Opgestane Jesus. Die gebeure rondom sy opstanding kan nog verder teruggevoer word - naamlik na die eskatologiese verwagting van 'n opstanding van die dode aan die einde van die tyd. "Histories," is vir Pannenberg in die verband 'n gebeure, wat enkel in die taal van die eskatologiese verwagting verwoord kan word, selfs al weet ons daar niks van nie. 
Die historiese bewys as sodanig is vir Pannenberg grootliks 'n oorleweringsbewys. Historiese bewyskrag het die bestaan van oorleweringsberigte as inhoud, soos wat die eskatologie die verwagting van 'n algemene opstanding uit die dode as inhoud het. Feit en interpretasie konstitueer tesame die historisiteit van 'n gebeurtenis. Oorleweringsgeskiedenis en werklike geskiedenis val ten einde laas saam (Bakker: 1996:244). Dit kom alles daarop neer dat, volgens Pannenberg, die uiteenval van die historiese werklikheid in betekenis en gebeurtenis onhoudbaar is. Geskiedenis kan slegs as oorgelewerde geskiedenis geken word. So is dit byvoorbeeld ten opsigte van Jesus se opstanding 'n gegewe, dat sy opstanding nie 'n sprakelose "gebeurtenis" is nie. Jesus se opstanding is oorgelewer in die oorleweringsamehang van die Joodse apokaliptiek, dit wil sê die leefwêreld waarin die geskiedenis beleef word as God se openbaringsmedium. Dat Jesus se opstanding in die spesifieke oorleweringsamehang staan, beteken dat Jesus optree met die aanspraak dat dit die eindtyd is. Dit is die tyd van God se teenwoordigheid, die tyd waarin die heil 'n realiteit word, omdat God in die opstanding van Jesus, die "prolepsis" van die einde, van sy heilbrengende eskatologiese teenwoordigheid bevestig. So spreek in die apokaliptiese oorleweringsamehang van God se handelinge in Jesus se opstanding, dit eintlik vanself: dooies word opgewek.

Vir Pannenberg is die bepalende van die historisiteit van Jesus se opstanding nie so seer die factum brutum as sodanig nie - want daarvan weet ons niks nie - maar die lig wat vanuit die einde die gebeurtenis bestraal. Wat die opstanding van Jesus tot 'n historiese betekenisvolle verskynsel maak, is die oorlewering van 'n algemene opstanding uit die dood as afsluiting van die geskiedenis.

Pannenberg gaan van die oortuiging uit dat wat 'n onbevooroordeelde historikus nie kan sien nie, moet hy ook nie glo nie - juis nie in die kerk nie - waar dit tog om die Waarheid en nie om wensdenkery gaan nie. As geloof moes bestaan uit die aanname van waarhede wat geensins ervaar kan word nie, is die inhoud van die geloof leeg. Dit is egter juis die kern van Pannenberg se teologie: die onvooroordeelde historikus kan terdez aantoon dat dit in die opstanding van Jesus gaan om waarheid en werklikheid. Jesus het immers opgestaan uit die dood: "Die vernünttige, vorurteilslose Erwägung des Geschehenen muss den Erweis der Gottheit des Gottes Israels darin erkennen" (Pannenberg 1975:85). 
As moderne historici dit ontken, is dit omdat hulle nie onbevooroordeeld is nie. Sodanige historici bekyk die werklikheid onder die voorteken van die analogie: iets is slegs te begrype binne kader van kontemporêre beskouings - iets wat is, soos dit nou maar eenmaal is. So 'n siening is egter in stryd met die wese en karakter van die geskiedenis, aldus Pannenberg. Hy stel: in geskiedenis gebeur dinge onverwags. Geskiedenis is kontingent (Van de Beek 1994:119). Dit is juis die kontingente wat geskiedenis tot geskiedenis maak - wat die verlede in 'n nuwe lig plaas en bevrydend die vasgeroeste strukture van die verlede in ander perspektiewe plaas. Dit bring mee dat die historikus voortdurend bedag sal wees vir die unieke van historiese gebeure en nie vooraf, vanuit sy eie situasie sal bepaal wat kan en wat nie kan nie.

Met betrekking tot die opstanding van Jesus, stel Pannenberg in die lig van voorafgaande opmerking, dat as met 'n onbevange gesindheid gekyk word na wat die geskiedenis leer in verband met Jesus se opstanding, kan 'n mens nie anders as om tot die konklusie te kom dat die Gekruisigde opgewek is nie; en dat Hy daarby lyflik te voorskyn getree het. As dit ontken word, word die verhale van die Nuwe Testament geweld aangedoen - en dit omdat vooraf besluit is die opstanding 'n onmoontlikheid is.

Pannenberg stel, dat die opstanding van Jesus nie in abstracto bestudeer kan word nie, asof dit maar 'n willekeurige insident was. So kan 'n mens, aldus Pannenberg, nie met die geskiedenis omgaan nie. Elke gebeurtenis in die geskiedenis, en as sodanig ook die opstanding, vind plaas binne 'n kontingente konteks, op 'n bepaalde plek en tyd. Die konteks is bepalend vir die interpretasie van die gebeure. Wie die opstanding van Jesus interpreteer in die konteks waar dit tuishoort en dit nie in abstracto, tydloos oordink nie, kan nie anders as om sy opstanding te sien as 'n bewys van die Godheid van die God van Israel nie.

Pannenberg stel drie kriteria waaraan oorleweringe uit die verlede moet voldoen om die egtheid van historiese gebeure te bepaal. In die eerste plek moet die literêre bronne outentiek wees, dit wil sê betrekking hê op die werklike gebeurtenis. Tweedens moet die historiese nie berus op sinsbedrog wat op geen wyse terug te voer is na die werklikheid nie. Derdens, sê hy dat die outensiteit van oorleweringe hang af van konkrete bewyslewering. As die opstandingsberigte van Christus hierop van toepassing gemaak word, blyk dit dat dit aan al drie genoemde kriteria voldoen. In die eerste plek: 
die opstandingsberigte spruit nie uit sekondêre bronne soos ondermeer mistiese, legendariese of visioenêre oorlewerings nie. Laasgenoemde soort corlewerings, noem Pannenberg irreęle oorlewerings wat ontoereikend is. Die teendeel geld volkome vir Jesus se opstanding. Dit is 'n gebeurtenis wat deur primêre bronne van oor en -ooggetuies verhaal word. Tweedens, die opstandingsgebeure hou verband met die tersaaklike van wat voorhande is: die verwysingsraamwerk van die Palestynse Jodendom van die eerste eeu. Binne die konteks stel die opstandingsgebeure die Fariseěrs, wat aan 'n opstanding uit die dode geglo het, en die Sadduseĕrs wat 'n opstanding van die dode ontken het, in ongelyk. Binne konteks van die Fariseërs se oortuigings, stel die opstanding van Jesus hulle voor die feit dat die Gekruisigde die Geregverdigde voor God is. Binne kader van die Sadduseërs se leer, stel sy opstanding laasgenoemdes voor die feit van God se groot mag. Derdens: Die outentisiteit van die oorlewering van die leë graf, spreek met buitengewone krag as bewysgrond van wat daardie Sondagoggend van die opstanding gebeur het. Dis egter nie al nie, die eintlike bewyskrag word ontleen aan die feitelikheid van die Joodse apokaliptiek. Alleen binne die verwagtingshorison van die apokaliptiek, kan die unieke van die opstanding van Jesus aan die lig tree. Dit dui weer op verstrengeling van feit en interpretasie, van taal en objektiwiteit. Dit is hoekom Pannenberg stel dat die werklikheid wat met Pase ervaar word, nie self as sodanig ' $n$ opstanding was nie, maar dit: opstanding was, soos gestel in die taal waarin die werklikheid geïnterpreteer was.

Vir Pannenberg is "opstanding" 'n absolute metafoor. Daarmee bedoel hy 'n "beeld" wat nie uitwisselbaar is met ander beelde nie, en ewemin herlei kan word tot rasionale kem wat daarvan te onderskei is: "Een metafoor dus, die de enige adequate uitdrukking vormt voor de werklykheid, die hier in het geding is" (Bakker 1996: 246).

Die werklikheid is immers vir Pannenberg eskatologies. Dus, die werklikheid word nog verwag en is tans nog verhul deur 'n diepe verborgenheid. Dit bring mee dat 'n metaforiese spreke oor Christus se opstanding onontkombaar is. Omdat die lewe van die Opgestane 'n nuwe skepping is, kan dit alleen op uitsonderlike wyse verstaan en uitgedruk word deur middel van visioene en simboletaal. Dit beteken egter, dat wanneer deur middel van simboletaal oor die "nuwe lewe" gepraat word, dit altyd noodwendig binne ' $n$ bepaalde tyd, binne ' $n$ reeks van 'n begrensde aantal gebeurtenisse en getuienisse sal geskied. As sodanig is sulke simboletaal beskrewe gebeurtenisse te kwalifiseer as historiese gebeurtenisse. 
Pannenberg voer die argument verder: as daar afgesien word van die begrip "histories", ten aansien van Jesus se opstanding, dan moet aanvaar word dat sy opwekking en verskyning nie werklik plaasgevind het nie. "Es gibt keinen Rechtsgrund die Auferweckung Jesu als ein wirklich geschehenes Ereignis zu behaupten, wenn sie nicht historisch als solches zu behaupten ist" (Pannenberg 1967:96).

Dat die opstanding werklik plaasgevind het, in ons wêreld, in ons tyd, in die jaar 30 voor die poorte van Jerusalem is 'n saak waaroor die Bybelse verkondiging nie die minste twyfel'oor laat nie. Dit behoort tot die wese van die Bybelse debarim dat dit op die aarde, onder ons, in ons midde plaasgevind het.

Teen Pannenberg se opvattings kan baie grondige kritiek ingebring word. Anders as Barth, interpreteer Pannenberg Jesus nie vanuit die Bundesgechichte nie, maar vanuit die Universalgeschichte. Daarby kan die teologie van Pannenberg ook nie aan die dwangmatigheid van die liniêr - historiese proses ontkom nie (kyk Bakker 1996:248). Selfs die siening aangaande die opstanding van Jesus kan daaraan nie 'n verandering bring nie. Die wending van die aeone vind ook eintlik nie plaas in die Geschick Jesu nie, maar aan die einde van die geskiedenis. Sy openbaring kan as sodanig as 'n voorlopige openbaring geïnterpreteer word.

\section{SAMEVATTING}

Ter aanvang is aangedui, dat die krisis van kerk sowel kultuur in die huidige tyd te wyte is aan die feit dat geskiedenis oorbodig geword het. In die opsig kan Pannenberg se denkarbeid oor geskiedenis 'n belangrike rol speel om te wys op die onontbeerlikheid van geskiedenis en as sodanig ook kerkgeskiedenis. Veral sy besinning oor die plek van Jesus Christus in die geskiedenis, as God self, wat Hom in die geskiedenis op 'n unieke wyse openbaar het en waardeur die werklikheid noêties en ontologies histories gemaak is, dwing elke denkende mens om Kerkgeskiedenis met erns te bejezn - omdat vir kerkgeskiedenis, is Christus se koms in dié tyd, van grondliggende betekenis: Trouens "geskiedenis" as sodanig, is ná die koms van Christus veel méér as net die chronologiese

rangskikking van feite. Hy is inderdaad die middelpunt van alle geskiedenis. Sy vleeswording is gekwalifiseerde heilshandelinge van die Skeppergod self. Hasselaar 
(1977:102) stel: “Christus geschiedende heerschappij moet op de één of ander wÿse constituerrend zynn voor alle geschieden."

Die uitspraak kan afgewys word as openbaringsmonisme. Maar terselfdertyd kan die vraag gevra word: hoe kan 'n mens anders reg laat geskied aan die feit dat op byna elke bladsy van die Ou Testament, die profetiese Woord nie alleen die lewe van Israel lei en regeer nie, maar ook die voortgaande wêreldgebeure op Israel betrek? En hoe wil 'n mens reg laat geskied aan die uitspraak van die apostel Paulus, dat alle dinge in Christus geskape is en aan Hom onderwerp is? Hoe sal 'n mens anders kan kom tot enige besef van die universele betekenis van Christus se opstanding: en hoe sal 'n mens ooit tot 'n volle trinitariese teologie kom, sonder Jesus Christus ekklesiologies én wêreldhistories én kosmies te verstaan, as die Weg en die Waarheid en die Lewe van die totale skepping? Natuurlik kan bogenoemde stellings wat vraenderwys aangedien is, verwarring skep tussen die geloof en allerhande wysgerige konsepsies. In die geval kan 'n mens maar gerus met Plato meespreek: die son maak homself en alle ander dinge sigbaar - so is dit ook met betrekking tot die Waarheid.

Pannenberg bring opnuut 'n mens onder die indruk dat in die Ou Testament vind ons ooral geskiedenis en rekenskap van geskiedenis. In die boodskap van die Nuwe Testament verdwyn dié geskiedenis nie, maar word telkens in die kategorie "vervulling" voortgesit. Van dié werklikheid moet nie net kennis geneem word nie, maar vanuit geleef word.

Dat die Messias opgestaan het in die midde van Israel (dit wat Pannenberg met soveel toewyding benadruk), is die primaat vir die verkondiging aan die wêreld en in die geskiedenis. Christus se opstanding bied die hoop op die komende Godsryk en as sodanig bied dit aan die historiese eskatologiese verstaan van die werklikheid inhoud en diepgang. Dit alles dwing 'n mens tot 'n posisie om die historiese verstaan ernstig op te neem, en bied terselfdertyd die vrymoedigheid tot historiese navorsing - nie ter wille van die interessante nie - maar terwille van die lewensbelangrike wat daaruit voortstu.

Teologiebeoefening ten dienste van die kerk, maak dodelike erns met die kern van God se openbaring: in en deur Christus is die heerskappy van God se koninkryk oor Israel en die volkere opgerig. Christus is die Here wat die wêreld klaar oorwin het (Joh 16:33). Hy is die Woord van God wat in ons tyd ingetree het (et incarnatus est) en oor 
alle tye en eeue regeer. Wanneer die gemeente in nood en aanvegting verkeer, soek dit vastheid en blydskap in die tekens van sy heerskappy. Tradisioneel was dit ook die Kerkgeskiedenis se taak om dié openbarings - feitelikhede te beskrywe.

Pannenberg lewer 'n bydrae in die verband met sy deurtastende nadenke aangaande die teken(s) van Christus se heerskappy betreffende sy opstanding en verskyning. Hiervoor verdien hy die waardering van kerkhistorici.

\section{Literatuurverwysings}

Bakker, N T 1966. Geschiedenis in opspraak. Kampen: Kok.

Barth, K 1961. Die Kirchliche Dogmatik, Band 3. Teil 3. Zürich: Evangelischer Verlag.

Cullmann O, 1946. Christus und die Zeit. Zürich Evangelisher Verlag.

De Knijff H W, 1980. Sleutel en slot. Kampen: Kok

Hasselaar, J M 1977. Overwegingen aangaande geloof en geskiedenis, in Al luisterend. Bundel opstelle ter geleentheid van prof $\mathrm{dr} J \mathrm{M}$ Hasselaar se sestigste verjaardag. Universiteit van Utrecth.

Kuiken, B 1993. Lyotard filosoof tegen wil en dank. Filosofie Magazine 2(8), 1993.

Lasch, $\mathrm{C}$ 1979. The culture of Narcissism: American life in a age of diminishing expectations. New York: Harper \& Row.

Pannenberg, W 1959. Heilsgeschehen und Geschichte, in Grundfragen systematischer Theologie. Gottingen: Vandenhoeck \& Ruprecht.

Pannenberg, W 1964. Grundzüge der Christologie. Gütersloh: Gütersloher Verslagshaus.

Pannenberg, W 1975. Glaube unde Wirklichkeit: Kleine Beiträge zum Christlichen Denken. München: Kaiser.

Robinson, J M 1967. New frontiers in theology, 111: Theology as history. New York: Harper \& Row..

Van de Beek, B 1994. Van verlichting tot verduistering? Nijkerk: G F Callenbach. 